\title{
The Savvy French Consumer: A cross-cultural replication
}

\author{
Marion Garnier* \\ Université Lille Nord de France \\ Lille School of Management Research Center \\ Avenue Willy Brandt 59777 Lille/Euralille, France \\ Email: m.garnier@esc-lille.fr / Phone: 0033 (0)3 20214087
}

\author{
Emma K. Macdonald \\ Cranfield School of Management \\ Cranfield University
}

Cranfield, Bedford MK43 0AL, England

Email: emma.macdonald@cranfield.ac.uk / Phone: 0044 (0)1234 751122

* Author for correspondence. 
The authors gratefully acknowledge the helpful comments from Professor Mark Uncles, the anonymous reviewers of the 2009 Academy of Marketing Conference and the Journal of Marketing Management special issue. 


\title{
The Savvy French Consumer: A cross-cultural replication
}

\begin{abstract}
While French consumers' adoption of broadband may slightly lag U.K. and Australian uptake, their adoption of various interactive technologies is rapidly increasing. The multidimensional 19-item consumer SAVVY scale helps to assess consumer competency including technological sophistication, marketing literacy, and networking - and can be used for population profiling. The scale is applied to a sample of French consumers (in French language) and a sample of UK consumers (in English). The findings indicate translational equivalence for the French-language version, as well as, good fit and reasonable stability of the scale in the French and UK replications. Thus the conceptual equivalence of "savvy" across cultures is supported. However, further analysis indicates that a parsimonious 10-item measurement model in the French context may be justified. The findings have implications for conceptualisation and assessment of consumer savvy across cultures. The implications for research and practice, as well as the study limitations, are discussed.
\end{abstract}

Key Words: Savvy consumer; Cross-cultural research; Scale replication; Consumer behaviour; Internet

Marion Garnier is a full time Assistant Professor at Lille School of Management / Université Lille Nord de France and member of the Lille School of Management Research Center (ESC Lille - ESA Lille 2). She completed her PhD in Marketing on web site loyalty (developing a relational model of loyalty to a search engine) in 2006 at Pierre Mendès-France Grenoble II University, France. She has broad-ranging interests in the context of online marketing including: consumer behaviour on the Internet; search engine and free websites marketing; avatars (consumer-avatars and embodied virtual sales agents) and 3D online merchant virtual environments; online consuming experience, usability and marketing; and, relational marketing online and in traditional retailing. She has published in the International Journal of Internet Marketing and Advertising, French academic journals and in international and national academic conferences proceedings (Advances in Consumer Research, Association Française de Marketing, Academy of Marketing).

Emma Macdonald is Senior Research Fellow in Marketing at Cranfield School of Management, University of Cranfield in the UK. She obtained her doctorate from the University of New South Wales in Sydney, Australia. Emma's PhD study developed a new measure of consumer competency ('savvy'). Her current research interests include consumer empowerment, customer value co-creation and assessment, real-time engagement and social networks. Emma conducted a post-doctoral research study at London Business School. Most recently she has been an EPSRC-funded researcher on a cross-school, multi-disciplinary project at Cranfield University assessing customer perceptions of value-in-use. She has published in the Journal of Marketing Management, Journal of Business Research and in professional publications and reports. Emma worked for several years in telecommunications and prior to that was a commercial researcher conducting brand, ad, and new product research for leading consumer brands. 


\section{THE SAVVY FRENCH CONSUMER: A CROSS-CULTURAL REPLICATION}

\section{INTRODUCTION - THE CONCEPT OF CONSUMER SAVVY}

New technologies and an expanded range of media mean that consumers are better informed, have potentially many more choices, and have more ways to acquire their choices (Day and Montgomery 1999). The strength and potential market power of technology-enabled consumers working collectively to influence the marketplace poses a threat to the firm that may "eat up your profit margins, cut down your market share, and marginalize your sources of strength" (Li and Bernoff, 2008, p.13). Savvy consumers are said to be adept in their interaction with the firm, confident in their role in the interaction, and have a desire to engage in co-creation (Li and Bernoff 2008; Prahalad and Ramaswamy 2004; Vargo and Lusch 2004; 2006, 2008). As a result of these trends, managers are under increasing pressure to modify their marketing strategies in response to the mass of demanding "new" consumers (Li and Bernoff 2008; Prahalad and Ramaswamy 2004; Wind and Mahajan 2004).

While several potential indicators of the sophistication of a consumer population may exist, household broadband penetration is a widely cited statistic. Worldwide household broadband penetration was estimated at $18 \%$ in 2007 and predicted to grow to $25 \%$ in 2012 (Gartner 2008). Australia, the UK and France are all considered by Gartner (2008) to be 'mature' broadband markets. Table 1 shows estimated and predicted household broadband penetration figures from several reports. From these analyses it appears that the three countries are fairly close on this indicator of technological sophistication. Strategy Analytics (2009) rates Australia slightly ahead at \#11 in the world, France \#13 and U.K. \#14. However Gartner contradicts this ranking by showing the U.K. ahead of France by approximately ten 
percentage points until $2012^{1}$. The important implication from these statistics is that broadband usage has not yet reached full penetration and is experiencing rapid growth in all three markets. Amanda Sabia, principal research analyst at Gartner observes that once penetration levels off "consumers in heavily penetrated markets are already addicted to broadband, thus the future in these markets is less concerned with increasing subscriber numbers, and more with addressing what new applications and/or content will be transmitted over this pipe," (Gartner 2008, online report).

\section{INSERT TABLE 1 ABOUT HERE}

The increasing penetration of broadband within the population and related changes in applications available to consumers implies potentially significant impacts for consumer behaviour including: information gathering and sorting, information sharing, purchasing and recommendation behaviour, media usage, and, finally, interaction with - and expectations of the firm. Additionally, the analysts are predicting a widening gap between the technology "haves" and "have-nots" (Gartner 2008). These twin trends of rapid change and increasing variance within the population imply an urgent need for measurement tools to assist researchers tracking these phenomena and managers who are making - or at least preparing for - the necessary operational and marketing changes in order to adapt.

This paper aims to address the need for a generalised measure of consumer savvy. It will commence with an overview of the concept of consumer savvy, and then examine the case of French consumer "savviness" in particular. The paper will then present the methodology and results of the cross-cultural replication of the SAVVY scale including construct equivalence, sampling equivalence and measurement equivalence. The implications

\footnotetext{
${ }^{1}$ Both Gartner and Strategy Analytics claim to report measures of household broadband penetration.
} 
for use of the full scale and a more parsimonious reduced scale will be discussed, along with the broader research and managerial implications.

\section{THE SAVVY SCALE}

The SAVVY scale (Macdonald and Uncles 2007) is a recognition that consumer savvy comprises multiple dimensions and is subject to individual differences. Consumer 'savvy' encompasses dimensions of competency (technological sophistication, offline and online network competency, and marketing literacy) and aspects of empowerment (self-efficacy and expectations of the firm) (Macdonald and Uncles 2007). The SAVVY scale, originally operationalised in Australia, has the potential for profiling individuals and segments across populations, and in assessing the development of consumer competency over time. Use of the scale is not yet widely diffused, and it has yet to be tested in other countries and cultural contexts. Our purpose is to replicate the 19-item SAVVY scale in two different cultural contexts: in the U.K., a country culturally similar to Australia, and in France, a country with a different language and a different culture, especially regarding consumption behaviours and attitudes.

The SAVVY scale was developed following a broad-ranging literature synthesis, by Macdonald and Uncles (2007) which identified six themes of consumer savvy. In examining the themes of savvy it becomes apparent that these are universal trends which could have potential implications across cultures. Each theme is now briefly discussed.

1. Technological sophistication. The first theme underlying almost all descriptions of the savvy consumer is that of consumers' technological sophistication and their ability through expanded media to realise their choices. For instance, the almost ubiquitous mobile 
phone technology enables real-time information and applications; the internet gives consumers easy access to vast amounts of information from many sources, and the growth in online shopping shows that consumers are successfully harnessing technology as a tool to assist their consumption outcomes.

Resulting from the capacity of consumers to adopt and use multiple technologies, they employ technology to improve the effectiveness of their consumption, for example, to source product information and make comparisons online (Day and Montgomery 1999; Prahalad and Ramaswamy 2004; Urban 2004), to link into their social networks (Iacobucci 1998; Wind and Mahajan 2002), and to exert control over information flows (Dupuy 2004; Hagel and Rayport 1997; Lawer and Knox 2004). These trends lead to the identification of the first theme, that savvy consumers have technological sophistication, and can use technology to their advantage in the market place.

2. Interpersonal network competency. This refers to the general ability of consumers to harness a network of useful personal contacts in relation to buying products/services and engaging in markets. We know that personal information sources are valuable; for instance, recommendation can have more impact on brand choice than advertising (East, Hammond, Lomax and Robinson 2005) and such sources are often seen as more credible than nonpersonal sources (Feick and Price 1987). The advantage for consumers in having a high level of offline network competency is the ability to use knowledgeable friends, relatives or acquaintances as information sources in a product purchase, thus providing consumers with an un-biased source of product information to compare against company-provided information. Thus the second theme is that savvy consumers have the ability to make use of interpersonal networks for efficient consumption. 
3. Online network competency. Greater connectivity removes barriers and creates the potential for consumers to access and share information right across the world and to form geographically-dispersed collectives. Technology-driven social phenomena, including blogs, wikis, social networks, file sharing and citizen journalism, are part of a trend towards people connecting and depending on each other rather than on institutions (Forrester 2006). The influence of these communities on the marketplace comes from the level of engagement they create amongst their members and their independence from the firm (Day and Montgomery 1999; Li and Bernoff 2008; Prahalad and Ramaswamy 2004).

As online connectivity increasingly makes the world a smaller place the consumer potentially has a much larger number of widely dispersed connections (Iacobucci 1998). New ideas gained from connecting with these widely dispersed sources of information may influence and change consumers' mental state and behaviours to a far greater extent than exposure to close ties (friends and family) (Brown and Reingen 1987; Godes and Mayzlin 2004). Consumers that possess online network competency are able to harness technology to participate in collectives with other consumers and to access new sources of information and ideas via the internet. Thus the third theme is that savvy consumers have the ability to make use of interpersonal networks for efficient consumption.

4. Marketing literacy. The new consumer is said to be literate (Harker and Egan 2004), educated (Harker and Egan 2004; Urban 2004) and informed (Prahalad and Ramaswamy 2004). Consumers are familiar with the ideas, objectives and methods of marketing and have the tools and abilities to conduct sophisticated analysis, dissection and critique of marketing activity (Harker and Egan 2004; Morales 2005; Urban 2004).

Additionally, consumers are said to know the game of advertising (Cotte and Robin 2005; Szmigin 2003). They are adept at decoding advertising: "The consumer is not passive, 
helpless advertising fodder" because they can detect the hype versus the reality in advertising and extract the information of value to them (Mackay 1997, p.28). When it comes to obtaining the information they require consumers turn to the internet first for product information (The Economist 2005b). Obviously, much of this internet-based information sourced by consumers is independent of the firm. Thus the fourth theme is that savvy consumers possess marketing literacy and can use this skill to their advantage in the marketplace.

5. Consumer self-efficacy. Savvy consumers are said to be more demanding and to have a greater desire to be in control of the consumer-firm interaction; furthermore, they can match this with more means to take control (Day and Montgomery 1999; Prahalad and Ramaswamy 2004; Urban 2004; Wind and Mahajan 2002). For instance, the potential for consumers to form technologically-enabled collectives has created some fear of increased consumer militancy (Szmigin 2003; Dupuy 2004); in these scenarios, firms are subject to " $a$ business version of the Invasion of the Body Snatchers" (Wind and Mahajan 2002, p72). Of more relevance is whether individual consumers themselves realise their potential to influence the marketplace and their potential to have an impact on the firms with which they interact. The mechanism for understanding consumers' self-perception consumer comes from the extensive body of research on self-efficacy led by Bandura (1977, 1997). Self-efficacy is defined as an individual's assessment of his or her ability to perform a behaviour (Bandura 1977). It equips individuals with the belief (whether or not it is objectively accurate) that they can produce valued effects by their individual and collective actions (Bandura 1997). If the commentaries are to be believed, this increasing self-belief in their ability to make a difference is activating more and more consumers, and thus leads to the fifth theme, that savvy consumers possess self-efficacy in dealing with firms. 
6. Consumers' expectations of information flows. Savvy consumers are said to have enhanced expectations of the firm in that they expect on-going dialogue with and support from the firm; or what Prahalad and Ramaswamy (2004) call deep engagement. Consumers have always expected firms to be responsive to their requests although they have often resigned themselves to being disappointed (Fournier, Dobscha and Mick 1998). However, consumers now have greater ability to enforce their expectations through ready access to information (about firms, products, markets) and through the ease of forming collectives with like-minded consumers. Additionally, with regard to their own personal information, savvy consumers increasingly understand the value of this information, and are aware that there is a vast amount of their personal information stored on company databases (Mitchell 2004).

In addition, consumers are increasingly operating multiple technologies, opening up a multitude of ways to connect with they firm. Thus consumers have morphed into "cybercentaurs" who effortlessly shift between real world and virtual channels and they expect firms to respond consistently via these multiple channels (Wind and Mahajan 2002). Thus the sixth and final theme is that savvy consumers expect free information flow between the firm and the consumer, and they expect ready access to the firm via multiple channels.

\section{CROSS-CULTURAL REPLICATION OF THE SAVVY SCALE: THE CASE OF THE SAVVY FRENCH CONSUMER}

The research question addressed in this paper is therefore: Does the notion of 'consumer savvy', as defined and operationalised by Macdonald and Uncles (2007), apply across other countries and cultures, and in particular the French culture? This is an important question for a newly conceptualized construct which has potential global application. 


\section{A brief review of savviness in the French marketing literature}

In the French marketing academic literature, several concepts are related to, and approximately cover some aspects of consumer savvy, including the opinion leader concept, (Bertrandias 2006), the lead user notion (Beji Becheur 1998) and work on smart shoppers (Djelassi, Odou and Belvaux 2008 - based on a conceptualisation by Mano and Elliott 1997). These concepts are used to describe consumers who are expert, influencing, innovative and/or clever in their way of consuming. However, these existing concepts in the French literature, although proximate to savvy, do not provide a holistic conceptualisation of the characteristics of consumer savvy. In particular, they neglect to assess the consumer's online connectivity, marketing literacies, enhanced expectations, and self-efficacy. To our knowledge, no other concept in the French literature can be compared to, or is equivalent to, consumer savvy as conceptualized by Macdonald and Uncles (2007).

As the trends leading to the emergence and growing influence of the savvy consumer are global in nature (see Table 1), there is a need for a comprehensive review of the existence and impact of consumer savvy across different cultures. This paper commences this review with an evaluation of the savvy conceptualisation and assessment of the applicability of the measurement scale amongst French consumers.

\section{Cultural issues impacting consumer savviness in a French context}

Cultural issues must be considered in replicating and using the SAVVY scale in France as there are differences in technology adoption and use between French-speaking cultures (and France more specifically) and English-speaking cultures (such as Australia and the U.K.) 
that could have an impact on the savvy consumer dimensions. Some differences that have been identified include:

(1) The technological sophistication and online network competency dimensions of the SAVVY scale might be influenced by the lower levels of technology penetration and usage in France, in comparison to Australia (as per Table 1) and the U.K. This is emphasised by various statistics: France is ranked $14^{\text {th }}$ in Europe for penetration of computer and Internet equipment (with a penetration rate of $43 \%$ versus $67 \%$ for the U.K.). France has a smaller proportion of online buyers and is ranked $8^{\text {th }}$ in Europe versus the U.K. which is $2^{\text {nd }}(40 \%$ of Internet users are e-buyers in France versus 57\% in the UK). Penetration of mobile phone Internet-usage and m-commerce is $9 \%$ in France but $13 \%$ in the U.K. ${ }^{2,3 \& 4}$.

(2) Consumer empowerment may also be subject to cultural influences. This may impact the self-efficacy dimension of the Savvy scale, which assesses the consumer's assertiveness and confidence in collaborating with the firm. In France, consumer relationships with firms may be considered in a slightly different way, as, for example, anecdotal evidence suggests that French consumers are less prone to complaining, or to legal action against firms.

Co-conception and customization in collaboration with firms is not widespread in France. A review by Renouvel (2009) suggests that mass co-conception and customization through the Net appeared in France in 2003 yet began several years earlier in Anglo-Saxon countries with various initiatives in industries such as clothes (Nike) or computers (Dell). For example, the customization initiative of personalizing $M \& M^{\prime} s^{5}$ chocolate candies with personal messages was launched worldwide in 2002, but was developed in France only five

\footnotetext{
${ }^{2}$ Source: Etude TNS Sofres (2008) L'avenir du m-commerce et m-marketing (M-commerce and M-Marketing future)

${ }^{3}$ French and European data available on www.journaldunet.com

${ }^{4}$ Though France is partly catching up: Internet is nowadays the first media used by French people ( $38 \%$ of media consumption $v s 37 \%$ for television), which is higher than in U.K., where television consumption is still ahead of Internet. Source: www.journaldunet.com

${ }^{5}$ Created in the 40 's in the USA, M\&M's produces and sells coloured chocolate candies.
} 
years later, and practitioners were sceptical about its fit with French culture ${ }^{6}$. The key customer co-creation initiatives that have met with success in France - such as, Nike ID, Longchamp (bag customisation) or Monopoly (customizing the game by voting for French cities) - are relatively recent, dating from 2008.

Dao's (2004) one-dimensional consumer self efficacy scale, developed in France, is composed of items related to purchasing and the purchasing process (information search efficacy, confidence and expertise in the best product choice, satisfaction with choice). Thus being an effective consumer in France may not be related to complaining and/or to consumerfirm collaboration. Instead it may be about being able to find necessary information and make the best choice (usually based on the optimal quality/price ratio or being able to find the best bargain);

(3) French consumers are also quite reluctant and not confident about giving out and use of their personal data for commercial purposes. This could have an impact on the expectations dimension of the SAVVY scale. Indeed, according to a recent survey by Harris Interactive (April $2009^{7}$ ), more than $80 \%$ of French people do not trust social networks or platforms such as DailyMotion in protecting their personal data, $97 \%$ believe it is dangerous to give their personal data on Internet payment systems and $72 \%$ even refuse to give them, especially in order to protect their private life and avoid commercial solicitations.

These cultural characteristics could lead to differences in the applicability of the sixdimensional savvy measure since they may lead to different meanings attributed by respondents to the items and their interpretation. As a consequence, the question of cultural influence on the savvy consumer concept and measure is highly relevant when applying it in the context of French consumers.

\footnotetext{
${ }^{6}$ Source : www.ecommercemag.fr, «La personnalisation, futur modèle de l'e-commerce ?» (Personalization, the future model of e-commerce?)

${ }^{7}$ Source : www.vnunet.fr, «Protection des données personnelles : les Français se méfient encore d'Internet » (Personal data protection: French still mistrust the Internet)
} 


\section{Cross-cultural issues in replicating a scale}

The question of whether a measurement scale is a genuine assessment of the same phenomenon across cultures and countries is fundamental for marketing academics and practitioners. Research dealing with cross-cultural validation of scales aims to understand and take into consideration potential sources of non-equivalence, so that the resulting measurement instruments can be used in a reliable and valid way in multiple contexts. Establishing the equivalence of a scale originally developed in another culture and another language presents challenges to the researcher. Three main potential sources of nonequivalence have been identified - construct equivalence, sampling equivalence and measure equivalence (Bartikowski, Chandon and Gierl 2005; Douglas and Craig 1983). In this research, we consider all three types of equivalence. However there is a particular emphasis on construct equivalence as a basic and necessary precursor to the potential use of the SAVVY scale across cultures. It is essential to confirm that the relevant ideas are expressed consistently across different cultures and languages (Bartikowski et al. 2005).

(1) Construct equivalence, includes:

- functional equivalence which is achieved when similar activities have identical goals in different countries and cultures. The resulting behaviour can then be assumed to be a response to a shared problem across cultures;

- conceptual equivalence: that concerns the interpretations made by individuals about objects, stimuli or behaviours. Conceptual equivalence is achieved when objects, stimuli and behaviours exist identically or are expressed in the same way across cultures and countries; 
The differences observed between French and U.K. consumers in levels of connectivity and, hence consumption patterns, suggests that this is an important and necessary stage for establishing the construct validity.

(2) Sampling equivalence, focuses on ensuring that the phenomena are assessed within comparable samples such that the research obtains:

- equivalence in the sample structure, for example, similar socio-demographic criteria;

- equivalence in size and representativeness of the samples, for example the optimal size of the samples should satisfy similar statistical criteria for each population.

The main goal of sampling equivalence is to ensure that possible differences observed cannot be attributed to methodological bias.

(3) Measure equivalence assesses:

- translation equivalence, which means paying attention to grouping lexical equivalence, idiomatic equivalence and grammatical equivalence in the translation of items. The translated version must preserve the meanings and ideas of the original version (Lacoeuilhe and Belaïd 2005).

- measure instrument equivalence: The measure must be adapted to the cultural context and norms (for example, it would be necessary to translate "inches" to "centimetres" in France). The procedure of measurement must be equivalent in terms of respondent engagement (recruitment, data collection mode), measurement context and response styles (scaling and adaptation to possible cultural response bias).

The methodology presented in the following section will lead to a reflection on the dimensionality and stability of the French-language SAVVY scale as well as giving consideration to the preservation of the original meanings of the scale. 


\section{METHODOLOGY}

As this was an initial application of the consumer SAVVY scale in an alternative cultural context and given the good psychometric qualities of the original SAVVY scale, the decision was made to test the French-language SAVVY scale with an adequate convenience sample. Depending on the outcomes of this initial study, further stages of the research, could possibly (a) include a qualitative phase in order to better understand differences, if any, in the nature of French consumer savvy, (b) proceed to generate new dimensions and items that might be appropriate to the French context, (c) before considering a multi-national replication on a much broader scale. Details of the methodology now follow.

\section{Sample selection}

It was originally intended that this study should be a French cultural replication of the study by Macdonald and Uncles (2007). However, as Australia is a long-way from France, geographically and culturally, it was decided to simultaneously conduct a replication of the SAVVY scale in the U.K. and France. The U.K. was chosen for its cultural proximity to Australia, however the U.K. is also influenced by European culture, and by its geographic proximity and specific links with France. Thus triangulation was provided by comparison between the original data collected a year earlier in Australia and two sets of data collected simultaneously in the U.K. and in France. Moreover, using a British sample to triangulate results helped to compensate for the methodological bias of a convenience sample in the current study. Direct comparison with the Australian sample would be inappropriate given non-equivalence in the sample structure between the original Australian study (which was a larger sample and aimed to be representative of age and gender distribution in the adult 
Australian population) and the French replication (which used a convenience sample of students aged predominantly 25 years and under). Respondents were recruited from business and engineering schools to complete an online survey. Sample compositions are presented in Table 2. These indicate a reasonable level of sampling equivalence in terms of sample structure and in terms of size and representativeness across the British and French samples (i.e. both samples are reasonably representative of the postgraduate university student population). As the data were collected simultaneously in France and in the U.K, it also ensured there was temporal equivalence between the two samples, which may be significant when dealing with phenomena (such as consumer savvy) which are under-going evolutionary change.

\section{INSERT TABLE 2 ABOUT HERE}

\section{Measurement instrument}

In order to minimize methodological biases and ensure measure instrument equivalence (respondent participation, context and procedures), design of the survey in English and in French was as much as possible, identical. Thus the two surveys followed the same recruitment process, question order, and number of questions per page, as well as using identical colours and visual display of the online questionnaire. The main difference was that the U.K. sample was subjected to the English-language survey originally used in Australia while the French sample responded to the newly developed French-language version.

In developing the French-language version of the 19-item SAVVY scale, a dynamic two-way translation procedure was implemented to obtain translation equivalence (Aulakh and Kotabe 1993; Bartikowski et al. 2005). Two professional English-French translators were employed (French was the mother-tongue for one of them while English was the mothertongue for the other). The aim was to find consistency between the original and translated 
items (see Appendix 1 for item details). The functional equivalence of the scale across the British and French samples was indicated by the ease with which the translators were able to agree on the individual dimensions and items of the scale. There did however, appear to be a challenge to establishing the conceptual equivalence for the scale. This was indicated by the translators' difficulties in agreeing on the overall translation for the word 'savvy'. As the word 'savvy' does not appear in any items of the SAVVY scale, this does not have an impact on the mechanisms of the actual measure however it is an interesting issue for describing the notion of savvy in the literature.

The literal translation of savvy in French covers two main meanings: knowledge/common sense or perspicacity. In the context of consumer savvy, both translators suggested various translations with subtle differences, without being able to achieve consensus or to settle on the best translation. According to the definition given of consumer savvy, consommateur avise $e^{8}$ was chosen as the most appropriate translation. Indeed, it seems to consistently express the whole set of characteristics defining consumer savvy.

While the translation of the meaning of 'savvy' appears to be mainly an issue for French researchers looking for an acceptable label for the scale, it could potentially have broader implications when translating the concept and measures into other languages. This implies some important challenges to preserving a consistent meaning for the SAVVY scale and could affect any attempts to modify the original SAVVY items.

\section{Procedure}

\footnotetext{
${ }^{8}$ Suggested translations were: consommateur qui a de la jugeote, consommateur rusé, consommateur avisé, consommateur à qui on ne la fait pas, consommateur perspicace, and consommateur expert. Avisé can be literally translated by sensible or wise, but our translators agreed that this term was relevant and meaningful in the context of consumer savvy.
} 
Respondents completed the survey online in their own time. They received course credits for their participation. After data cleaning and preliminary analysis to check the appropriateness of the data for statistical analysis (outliers, normality), Confirmatory Factor Analysis (CFA) was conducted with AMOS 5.0. Evaluation of model fit and reliability was conducted separately for the two samples and results are presented and discussed in the following section. Having established good model fit for the 19-item measurement model, an analysis of cross-cultural measurement invariance was conducted using CFA multi-group analysis in AMOS. Finally, further purification of the SAVVY scale was conducted using the findings from the French sample. This latter procedure suggested a reduced scale comprising 10 items across 3 dimensions. The implications and limitations of the current study are then discussed.

\section{RESULTS AND DISCUSSION}

\section{Model fit}

Analysis of measurement model fit (Table 3) found that the SAVVY measurement model has very good fit for the French sample $\left(\chi^{2}=175.9\right.$, d.f. $\left.=137, p=0.01\right)$. This includes goodness-of-fit, assessed by the Comparative Fit Index, at the preferred threshold (CFI = 0.95), a badness-of-fit estimate $\mathrm{SRMR}=0.03$ within the acceptable range, and RMSEA $=0.04$ also in the preferred range. (The thresholds and cut-offs are recommended by Hair, Black, Babin, Anderson and Tatham (2006) based on sample size and number of observed variables). Surprisingly, given the a priori assumptions about the 'closeness' of British and Australian culture, the measurement model for the British sample does not fit quite as well as the French sample. Measurement model fit is close to the acceptable range $\left(\chi^{2}=232.1\right.$, d.f. $=137$, 
$\mathrm{p}=0.00$ ) with $\mathrm{CFI}=0.92$ (below the ideal threshold of 0.95 ), $\mathrm{SRMR}=0.06$ in the acceptable range, and $\mathrm{RMSEA}=0.06$ also in the acceptable range.

\section{INSERT TABLE 3 ABOUT HERE}

\section{Factor structure and reliability}

Despite the good fit overall of the French savvy measurement model, examination of the factor structure (Table 4) identified low factor loading on three items in two dimensions (Marketing Literacy (ML) and Interpersonal Network Competency (NW)), and low reliability for those two dimensions $(<0.5)$ (see Table 4$)$, while the reliability of the Consumer Self Efficacy dimension (CF) is also below the standard of 0.7 (Nunnally 1978). Overall reliability of the scale is 0.72 . This indicates that there may be some differences in the meaning of items between the original scale and the French language version.

\section{INSERT TABLE 4 ABOUT HERE}

The British measurement model indicates acceptable reliability for each dimension and overall scale reliability of Cronbach alpha $=0.84$ (Table 4$)$. However it also exhibits low factor loading on the identical item in interpersonal network competency (NW1 "I always know someone to call if I want to find the best product or service.") One explanation for the low loading on this particular item could be due to the sample profile in the current study. The interpersonal network competency dimension of the SAVVY scale takes account of individuals who may not have strong online network competency skills (i.e. who could even be technology phobic) yet who are adept at locating sources of information amongst their acquaintances. As the respondents in both samples reported in the current study are: (a) young, and therefore have had less time to develop interpersonal networks, and (b) university- 
educated and therefore likely to be amongst the most technologically-sophisticated groups within their respective countries, the interpersonal network competency dimension may be less relevant to understanding them.

\section{Measurement invariance analysis}

Measurement invariance analysis is used to establish whether a measurement tool has the same meaning across different groups. The technique of scale invariance analysis adopted in this study uses multi-group CFA in AMOS structural equation modelling (Byrne 2003). Measurement invariance tests using multigroup CFA are usually conducted in a series of steps, by progressively testing increasingly constrained models that are nested in previously estimated less constrained models (Byrne 2004; Vandenberg and Lance 2000). As the models are nested within one another, the difference in chi-square between the nested models is also distributed in a chi-square distribution with degrees of freedom equal to the difference in the degrees of freedom of the compared models (Byrne 2004).

The process of multigroup measurement invariance analysis using CFA involved simultaneously estimating model fit for the two samples - French and British. Model fit was initially calculated for a Baseline model where none of the measurement parameters were constrained to be equal across the groups. Then comparisons were conducted between the Baseline model and a model which has all measurement weights constrained equal in order to establish whether full factorial invariance exists (Table 5). In this case there was a significant chi-square difference between these two models, so we know that some equality constraints do not hold across the population groups and therefore full factorial invariance is not established. 
However, for cross-cultural research it is sufficient to establish that a measurement scale demonstrates partial factorial invariance such that just two items on each dimension are constrained to equal (Hair et al 2006). A comparison between the partial model and the baseline once again indicates a significant chi-square difference such that partial factorial invariance does not exist (Table 5). These findings indicate that there are some differences in the meaning of the scale between the French and British samples.

The findings suggest that in subsequent phases of this research, qualitative research with both French and British respondents is justified to clarify the meanings of constructs and items. (For instance, a limitation of the current study is that while it was assumed that Australian and British respondents might respond similarly due to cultural proximity, it did not test this in terms of the SAVVY scale. It is possible, given the findings reported here of superior model fit for the French sample - and not the British sample - that with regards to their 'savviness', the French respondents share greater similarity with the original Australian sample than they do with the British respondents.)

\section{Further purification of the French SAVVY scale}

There are indications that the savvy construct and SAVVY-scale items have relevance to the French population (i.e. we established construct validity, found very good overall model fit, and with a few exceptions, we observed acceptable reliability and item loadings). However, in order to explore whether a modified SAVVY scale might be more appropriate in the French context an iterative process of scale purification was conducted with Principal Component Analysis (SPSS 17.0). The aim was to eliminate those items and constructs that had poor loadings. After several iterations, where items were removed one-by-one, a 3dimensional, 10-item structure was found and tested using CFA. The three dimensions were 
Online Network Competency (NO), Technological Sophistication (TS) and Expectations (EX) (Table 4). Overall reliability of the scale is acceptable, with a Cronbach alpha of 0.75 . Though model fit (Table 3$)$ is acceptable for the 3 -dimension and 10 -item structure $\left(\chi^{2}=79.9\right.$, d.f. $=$ 32, $\mathrm{p}=0.01$ ), the goodness-of-fit indicator $\mathrm{CFI}=0.92$ is now below the preferred threshold, and SRMR $=0.05$ and RMSEA=0.08 indicate the fit is not as good as the 6-dimensional, 19item model, although fit statistics are close to acceptable.

The examination of factor structures for the 3-dimensional, 10-item model in the French data (Table 4) shows improved stability for the Online Network Competency and Expectations dimensions, as well as Technological Sophistication, even though one item was dropped (Table 4). This modified version of the SAVVY scale has the advantage of being more parsimonious which could potentially benefit researchers trying to reduce survey length. What is important to note is that the core meaning of SAVVY on consumer connectivity and empowerment is maintained, and thus the fundamental meaning of the scale is preserved. Nevertheless, the discarding of the other dimensions (Interpersonal Network Competency, Marketing Literacy and Consumer Self Efficacy) raises questions about the importance of these dimensions in understanding savvy in a French-cultural context.

Since the 6-dimensional, 19-items factor structure fits the French data in a very acceptable way, conceptual equivalence of the scale is shown to be effective. The question seems to be more one of measurement equivalence, i.e. translation, meaning and appropriateness of items in light of possible cultural influences. As predicted, self-efficacy seems to be perceived differently by French consumers; items dealing with complaining or collaboration with firms might not be appropriate and characteristic of a proficient French consumer. It is possible that items related to smart shopping could have been more appropriate for French consumers. 
The fact that Interpersonal Network Competency and Marketing Literacy were discarded in the reduced scale is more surprising, as such dimensions are most likely to be influenced by individual characteristics, such as personality, individual interpersonal relationship tendencies or individual education and knowledge, than by cultural factors. However, the sampling limitations of the current study need to be taken into consideration. It is possible that young, student respondents have not yet developed marketing literacy and the interpersonal networks to assist them in efficient consumption. Also this subset of the overall population is more educated and likely to be more technologically sophisticated and have stronger competencies in online networking. Thus it would be precipitous to make any final conclusions about scale dimensionality until further analysis with a broader sample definition has been conducted.

\section{CONCLUSION}

According to the findings from our replication of the 6-dimensional, 19-item SAVVYscale in France, there is evidence for its conceptual and measurement equivalence across cultures. This is supported by the ease of translation equivalence for the items of the scale and very good model fit for the original SAVVY scale with the French sample. In addition, good reliability and strong factor loadings were identified for the more parsimonious 3-dimensional 10-item scale. The consumer savvy concept and SAVVY scale are promising ways to understand consumers in a consistent and valid way across cultures. The good fit of the original model and the stability on core characteristics are indicators of the adaptability and adequacy of the SAVVY scale. Although the findings from this first replication cannot be conclusive, they do indicate the potential for the SAVVY scale to become a comprehensive tool for assessment of consumer competency in a networked, global marketplace. 
There are limitations in the current study design - including use of a convenience sample - which will be addressed in further stages of the research. These further stages will include:

(1) Qualitative research with French consumers to explore the savvy dimensions and to determine their understanding of the constructs and items, so to better understand cultural differences that could have an influence. Possibly, such a study will generate new items specifically and culturally adapted to French consumers, especially for dimensions such as self-efficacy or marketing literacy. Similar research is required in the U.K. and in any subsequent countries where the SAVVY scale might be applied.

(2) Further replication needs to be conducted with samples that are representative of the general consumer population, as per Macdonald and Uncles (2007), in order to improve the generalisability of the findings

The concept of consumer savvy has important synergies with the Service-Dominant Logic and the notion that the consumer is always a co-creator of value (Vargo and Lusch 2004, 2006, 2008). Consumer empowerment and the resulting requirement for more consumer-centric approaches to marketing have been increasingly prevalent themes amongst academics and practitioners. In order to remain competitive, firms are warned that they need to work more closely with and be more responsive to their consumers (e.g. Prahalad and Ramaswamy 2004). Importantly, the notion of consumer savvy is consistent with a view in marketing that the consumer plays a bigger role in the specification, production and delivery of consumer products and services (Vargo and Lusch 2004, 2008).

Consumer savvy also has relevance to design of integrated marketing communications, since one of the consequences of the 'connected knowledge economy' is the faster and freer flow of information to the consumer as well as the firm. With more information available real-time to consumers than previously, they are in a much stronger position to: (a) question 
(or even ignore) information from the firm, (b) find their own sources of information, and (c) generate their own forms of consumer-to-consumer communication regarding a brand. From a management perspective, the potential for disruption to communications, channels, corporate knowledge management, and perceptions of value is significant.

Finally, the notion of consumer savvy has important links to the literature on consumerism which Hilton (2007) observes has been a neglected area of research. Alliances of consumers can be powerful and this trend is trans-national (Li and Bernstein 2008). This study provides an early indication that the SAVVY scale may have some robustness as a global profiling tool which will assist researchers and practitioners in preparing for the onslaught of a "groundswell" of active, demanding, connected consumers.

\section{REFERENCES}

Aulakh, P.S. and Kotabe M. (1993), “An assessment of theoretical and methodological development in international marketing: 1980-1990", Journal of International Marketing, Vol. 1, No 2, pp. 5-28.

Bandura, A. (1977), "Self-efficacy: Toward a unifying theory of behavioral change", Psychological Review, 84, pp. 191-215.

Bandura, A. (1997), Self-efficacy: The exercise of control, New York: W.H. Freeman and Company.

Bartikowski, B., Chandon, J-L. and Gierl, H. (2005), "Les problèmes sémantiques de la mesure de la satisfaction des consommateurs", Actes de la Conférence de l'Association Française de Marketing, May, Nancy.

Beji Becheur, A. (1998), "L'utilisateur leader et le degré de novation du produit : une contribution à l'amélioration de l'analyse des tests de nouveaux produits - application au produit automobile", Thèse de Doctorat en Sciences de Gestion, Université de Paris IX Dauphine

Bertrandias, L. (2006), "Sélection et influence des sources personnelles d'information du consommateur", Thèse de Doctorat en Sciences de Gestion, IAE de Toulouse

Brown, J. J. and Reingen, P. (1987), "Social Ties and Word-of-Mouth Referral Behavior", Journal of Consumer Research, Vol. 14, pp. 350-362. 
Byrne, B.M. (2003), "The issue of measurement invariance revisited", Journal of CrossCultural Psychology, Vol. 34, No 2, pp. 155-175.

Byrne, B.M. (2004), “Testing for multigroup invariance using AMOS Graphics: A road less travelled”, Structural Equation Modelling: A Multidisciplinary Journal, Vol. 11, pp. 272300.5 .

Cotte, J. and Robin, R. (2005), “Advertisers' theories of consumers: Why use negative emotions to sell?", Advances in Consumer Research, 32, pp. 24-31.

Dao, T. (2004), "Importation du concept du sentiment d'efficacité personnelle en comportement du consommateur. Proposition d'une échelle de mesure", Actes de la Conférence de l'Association Française de Marketing, May, Saint-Malo.

Day, G.S. and Montgomery, D.B. (1999), “Charting new directions for marketing”, Journal of Marketing, 63, pp. 3-13.

Djelassi, S., Odou, P. and Belvaux, B. (2008), "Exploration du comportement du Smart Shopper : le cas des ODRistes", 7th International Congress Marketing Trends, Venise.

Douglas, S.P. and Craig, S. (1983), International Marketing Research, Prentice-Hall, Englewood Cliffs, NJ.

Dupuy, F. (2004), Sharing knowledge: They why and how of organizational change, Hampshire, UK: Palgrave Macmillan.

East, R., Hammond, K., Lomax, W. and Robinson, H. (2005), "What is the effect of a recommendation?", Marketing Review, Vol. 5, No 2, pp. 145-157.

Feick, L.F. and Price, L.L. (1987), "The market maven: a diffuser of marketplace information", Journal of Marketing, Vol. 51 (Jan), pp. 83-97.

Forrester (2006), "Social computing: How networks erode institutional power, and what to do about it", Chris Charron, Charlene Li and Jaap Favier, [http://www.forrester.com/Research/Document/Excerpt/0,7211,38772,00.html] (Accessed 1 August 2008).

Fournier, S., Dobscha, S. and Mick, D.G. (1998), "Preventing the premature death of relationship marketing", Harvard Business Review, 76(1), Jan-Feb, 42-51.Gartner (2007), "Worldwide Consumer Broadband Penetration Sees Rapid Growth but Current Price Strategy Alone is Not Sustainable for Telecom Carriers Says Gartner“, (8February-2007), [http:/www.gartner.com/it/page.jsp?id=501276], (accessed 14-August2009). 
Gartner (2008), “Gartner Says 17 Countries to Surpass 60 Percent Broadband Penetration into the Home by 2012“, 24-July-2008, [http://www.gartner.com/it/page.jsp?id=729907] (accessed 14-August-2009).

Godes, D. and Mayzlin, D. (2004), "Using online conversations to study word of mouth communication", Marketing Science, Vol. 23, No 4, pp. 545-560.

Hagel, J. III and Rayport, J.F. (1997), “The coming battle for customer information”, Harvard Business Review, Jan-Feb, pp. 53-65.

Hair, J.F., Black, W.C.., Babin, B.J., Anderson, R.E. and Tatham, R.L. (2006), Multivariate data analysis, 6th edition. New Jersey, USA, Prentice-Hall.

Harker, M.J. and Egan, J. (2004), "Savvy: Customer marketing literacy and relationship marketing", in Proceedings of Academy of Marketing Conference 2004, Barry Davies and Janine Dermody, eds. 6-9 July, University of Gloucestershire Business School.

Hilton, M. (2007), "Social activism in an age of consumption: The organized consumer movement", Social History, Vol. 32, No 2, pp. 121-143.

Iacobucci, D. (1998), "Interactive marketing and the meganet: Networks of networks", Journal of Interactive Marketing, Vol. 12, No 1 (Winter), pp. 5-16.

Lacoeuilhe, J. and Belaïd, S. (2005), "Une validation interculturelle de l'échelle d'attachement à la marque", Actes de la Conférence de l'Association Française de Marketing, May, Nancy.

Lawer, C. and Knox, S. (2004), "Reverse marketing, consumer value networks and the new brand intermediaries", in Value Network and ICT Symbiosis: Issues and Applications for Operational Excellence, Y.S. Chang et al., eds. New York: Kluwer.

Li, C. and Bernoff, J. (2008), Groundswell: Winning in a world transformed by social technologies, Harvard Business Press: Boston.

Macdonald, E.K. and Uncles, M.D. (2007), "Consumer savvy: conceptualisation and measurement", Journal of Marketing Management, Vol. 23, No 5-6, pp. 497-517.

Mackay, H. (1997), Generations: Baby boomers, their parents \& their children, Sydney: Pan Macmillan.

Mano, H. and Elliott, M.T. (1997), "Smart shopping: the origins and consequences of price savingsV, Advances in Consumer Research, 24, pp. 504-510.

Mitchell, A. (2004), "The buyer-centric revolution: The rise of reverse direct", Interactive Marketing, Vol. 5, No 4, pp. 345-358.

Morales, A.C. (2005), "Giving Firms an "E” for Effort: Consumer Responses to High- Effort Firms", Journal of Consumer Research, Vol. 31, pp. 806-812. 
Nunnally, J.C. (1978), Psychometric theory ( $2^{\text {nd }}$ ed.), New York : McGraw-Hill.

Prahalad, CK and Ramaswamy, V (2004), "Co-creation experiences: the next practice in value creation", Journal of Interactive Marketing, Vol. 18, No 3, pp. 5-11.

Renouvel, G. (2009), “La personnalisation, futur modèle de l'e-commerce?“, E-commerce $\mathrm{N}^{\circ} 17, \quad 01 / 04 / 2009, \quad$ [Available at : http://www.ecommercemag.fr/xml/Archives/Ecommerce/17/30886/La-personnalisation-futur-modele-de-1-e-commerce-/], (Accessed 1Jan-2009).

Strategy Analytics (2009), "US Ranks 20th in Global Broadband Household Penetration" (18June-2009),

[http://www.strategyanalytics.com/default.aspx?mod=PressReleaseViewer\&a0 $=4748]$,

(Accessed: 14-August-2009).

Szmigin, I. (2003), Understanding the consumer, London: Sage Publications.

The Economist (2005a), "Crowned at last”, 2-April-2005, 375 (8420), Special section 3-6.

The Economist (2005b), "Power at last", 2-April-2005, 375 (8420), pp. 11-11.

Urban, G.L. (2004), "The emerging era of customer advocacy", MIT Sloan Management Review, Vol. 45, No 2 (Winter), pp. 77-82.

Vandenberg, R.J. and Lance, C.C. (2000), "A review and synthesis of the measurement invariance literature: Suggestions, practices, and recommendations for organizational research", Organizational Research Methods, Vol. 3, No 1, pp. 4-70.

Vargo, S.L. and Lusch, R.F. (2004), "Evolving to a new dominant logic for marketing, Journal of Marketing”, Vol. 69 (Jan), pp. 1-17.

Vargo, S.L. \& Lusch, R.F. (2006). "Service-dominant logic: What it is, what it is not, what it might be.” In R.F. Lusch \& S.L. Vargo (Eds.), The service-dominant logic of marketing: dialog, debate, and directions. Sharpe, New York.

Vargo, S.L. \& Lusch, R.F. (2008). "Service-dominant logic: Continuing the evolution." Journal of the Academy of Marketing Science, Vol. 36, pp. 1-10.

Wind, Y. and Mahajan, V. (2002), "Convergence marketing”, Journal of Interactive Marketing, Spring, Vol. 16, No 2, pp. 64-79. 
Table 1. Household broadband penetration rates: Australia, U.K. and France

\begin{tabular}{|c|c|c|c|c|c|c|c|c|}
\hline \multicolumn{9}{|c|}{ Strategy Analytics 2009} \\
\hline & 2005 & 2006 & 2007 & $2008^{a}$ & 2009 & 2010 & 2011 & 2012 \\
\hline Australia & & & & $72 \%(\# 11)$ & & & & \\
\hline U.K. & & & & $67 \%(\# 14)$ & & & & \\
\hline France & & & & $68 \%(\# 13)$ & & & & \\
\hline \multicolumn{9}{|c|}{ Gartner 2007 / 2008} \\
\hline & $2005^{b}$ & 2006 & $2007^{b}$ & 2008 & 2009 & $2010^{b}$ & 2011 & $2012^{c}$ \\
\hline Australia & --- & & --- & & & --- & & $72 \%$ \\
\hline U.K. & $36 \%$ & & $56 \%$ & & & $64 \%$ & & $74 \%$ \\
\hline France & $33 \%$ & & $45 \%$ & & & $53 \%$ & & $73 \%$ \\
\hline
\end{tabular}

a. Strategy Analytics (18-Jun-2009), Household penetration (Worldwide ranking)

b.Gartner (8-Feb-2007), Household penetration Western Europe.

c.Gartner (24-Jul-2008), Household penetration.

Table 2. Sample descriptions - Australia, U.K. and France

\begin{tabular}{|c|c|c|c|}
\hline & Australia $^{a}$ & U.K. $^{\mathbf{b}}$ & France $^{b}$ \\
\hline $\mathbf{N}=$ & 563 & 205 & 211 \\
\hline \multicolumn{4}{|l|}{ Gender } \\
\hline Male & $50 \%$ & $42 \%$ & $39 \%$ \\
\hline Female & $49 \%$ & $58 \%$ & $60 \%$ \\
\hline Not stated & $1 \%$ & -- & $1 \%$ \\
\hline \multicolumn{4}{|l|}{ Age } \\
\hline 19 or younger & \multirow{3}{*}{$27 \%$} & $8 \%$ & $10 \%$ \\
\hline $20-24$ & & $42 \%$ & $89 \%$ \\
\hline $25-29$ & & $23 \%$ & $1 \%$ \\
\hline $30-39$ & $30 \%$ & $23 \%$ & -- \\
\hline $40-49$ & $24 \%$ & $3 \%$ & -- \\
\hline $50-59$ & \multirow{2}{*}{$19 \%$} & -- & -- \\
\hline $60-69$ & & $1 \%$ & -- \\
\hline
\end{tabular}

a. Data reported in Macdonald and Uncles (2007), a representative sample.

b. Data collected simultaneously in U.K. and France in 2008, a postgraduate student sample. 
Table 3. Summary of CFA model fit results across Australian, U.K. and French samples

\begin{tabular}{|l|c|c|c|c|c|c|c|c|}
\cline { 2 - 8 } \multicolumn{1}{l|}{} & $\chi^{\mathbf{2}}$ & $\mathbf{d . f .}$ & $\mathbf{p}^{\mathbf{b}}$ & $\chi^{\mathbf{2} / \mathbf{d . f} .}$ & GFI & SRMR & $\begin{array}{c}\text { RMSEA } \\
\text { (Upper, } \\
\text { Lower) }\end{array}$ & CFI \\
\hline $\begin{array}{l}\text { Australian data } \\
\text { (n=563) }\end{array}$ & & & & & & & & \\
$\begin{array}{l}\text { SAVVY model } \\
\text { (6 Factors, 19 Items) }\end{array}$ & 393.33 & 137 & .000 & 2.85 & 0.93 & 0.05 & $\begin{array}{c}0.06 \\
(0.05,0.06)\end{array}$ & 0.93 \\
\hline $\begin{array}{l}\text { U.K. data (n=205) } \\
\text { SAVVY model } \\
\text { (6 Factors, 19 Items) }\end{array}$ & 232.05 & 137 & .000 & 1.69 & 0.89 & 0.06 & $\begin{array}{c}0.06 \\
(0.05,0.07)\end{array}$ & 0.92 \\
\hline $\begin{array}{l}\text { French data (n=211) } \\
\text { SAVVY model 1 } \\
\text { (6 Factors, 19 items) }\end{array}$ & 175.93 & 137 & .014 & 1.28 & 0.92 & 0.03 & $\begin{array}{c}0.04 \\
(0.02,0.05)\end{array}$ & 0.95 \\
$\begin{array}{l}\text { SAVVY model 2 } \\
\text { (3 Factors, 10 Items) }\end{array}$ & 79.936 & 32 & .000 & 2.50 & 0.93 & 0.05 & $\begin{array}{c}0.08 \\
(0.06,0.10)\end{array}$ & 0.92 \\
\hline
\end{tabular}

a. Macdonald and Uncles (2007)

b. Significant $p$-values are to be expected in a model which has a sample size $n>200$ and a large number of indicators (Hair et al. 2006). 
Table 4. Factor Structure and reliability of SAVVY - U.K. and French samples

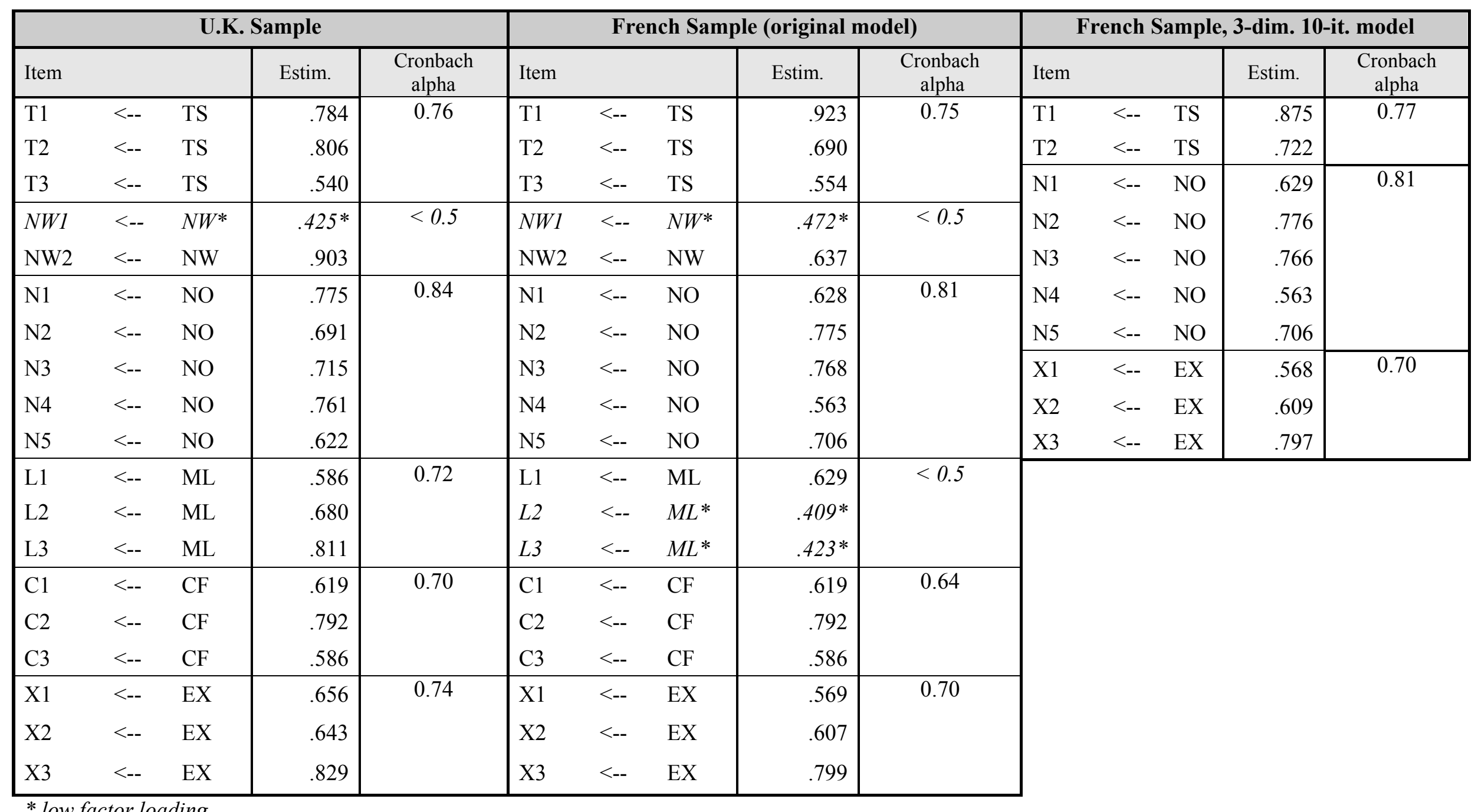

* low factor loading 
Table 5. SAVVY scale invariance analysis - UK and French samples

\begin{tabular}{|l|c|c|c|c|c|c|c|}
\hline Model name & $\chi^{\mathbf{2}}$ & d.f. & $\mathbf{p}$ & Model compared & $\chi_{\mathbf{d}}^{2}$ & $\Delta$ d.f. & p \\
\hline Baseline: Unconstrained (Baseline) model & 407.99 & 274 & .00 & & & & \\
\hline Test of full factorial invariance & & & & & & & \\
\hline Model 1: Measurement weights constrained & 441.29 & 287 & .00 & Baseline & 33.30 & 13 & .002 \\
\hline Test of partial factorial invariance & & & & & & & \\
\hline $\begin{array}{l}\text { Model 2: Measurement weights constrained } \\
\text { except CRI2, CRI3 }\end{array}$ & 434.78 & 285 & .00 & Baseline & 26.79 & 11 & .005 \\
\hline
\end{tabular}


Appendix 1. SAVVY scale and its translation in French

\begin{tabular}{|c|c|c|}
\hline Items & Translated items & \\
\hline \multicolumn{3}{|c|}{ Technological Sophistication (TS) } \\
\hline Other people come to me for advice on new technologies. & $\begin{array}{l}\text { Les autres viennent me voir pour obtenir des conseils sur les nouvelles } \\
\text { technologies. }\end{array}$ & $\mathrm{T} 1 *$ \\
\hline $\begin{array}{l}\text { In general, I am first among my circle of friends to acquire new } \\
\text { technology when it appears. }\end{array}$ & $\begin{array}{l}\text { En général, je suis le (la) premier(ère), dans mon cercle d'amis, à } \\
\text { acquérir une nouvelle technologie lorsqu'elle fait son apparition. }\end{array}$ & $\mathrm{T} 2 *$ \\
\hline $\begin{array}{l}\text { I can usually figure out new high-tech products and services without } \\
\text { help from others. }\end{array}$ & $\begin{array}{l}\text { D'habitude, je n'ai pas besoin d'aide pour me débrouiller avec les } \\
\text { produits et les services de haute technologie. }\end{array}$ & $\mathrm{T} 3$ \\
\hline \multicolumn{3}{|c|}{ Interpersonal Network Competency (NW) } \\
\hline $\begin{array}{l}\text { I always know someone to call if I want to find the best product or } \\
\text { service. }\end{array}$ & $\begin{array}{l}\text { Je sais toujours qui appeler si je veux en savoir plus sur le meilleur } \\
\text { produit ou service. }\end{array}$ & NW1 \\
\hline $\begin{array}{l}\text { I have a useful network of contacts who can give me up-to-date } \\
\text { product information on the latest innovations. }\end{array}$ & $\begin{array}{l}\text { Je possède un réseau de contacts utiles qui peuvent me donner des } \\
\text { informations à jour sur les dernières innovations en matière de produits. }\end{array}$ & NW2 \\
\hline \multicolumn{3}{|c|}{ Online Network Competency (NO) } \\
\hline $\begin{array}{l}\text { I often check-out chatrooms and bulletin boards to find out about the } \\
\text { latest products that are coming. }\end{array}$ & $\begin{array}{l}\text { Je consulte souvent les forums et la messagerie instantanée (tchat) pour } \\
\text { en savoir plus sur les nouveaux produits qui sortent. }\end{array}$ & $\mathrm{N} 1 *$ \\
\hline $\begin{array}{l}\text { I'll often see if there is an online community that can help me when } \\
\text { I'm looking for a product recommendation. }\end{array}$ & $\begin{array}{l}\text { Je cherche souvent à savoir s'il existe une communauté en ligne qui peut } \\
\text { m'aider quand je souhaite obtenir des conseils sur un produit. }\end{array}$ & $\mathrm{N} 2 *$ \\
\hline $\begin{array}{l}\text { I'll often seek the opinions of other consumers by posting a query } \\
\text { about a product on an online bulletin board or chat room. }\end{array}$ & $\begin{array}{l}\text { Je cherche souvent les avis d'autres consommateurs en postant une } \\
\text { demande à propos d'un produit sur la messagerie instantanée (tchat) ou } \\
\text { sur des forums }\end{array}$ & $\mathrm{N} 3 *$ \\
\hline $\begin{array}{l}\text { I enjoy sharing points of view with online acquaintances via bulletin } \\
\text { boards and chatrooms. }\end{array}$ & $\begin{array}{l}\text { J'aime partager mon point de vue avec mes connaissances en ligne à } \\
\text { travers les messageries instantanées (tchats) et les forums. }\end{array}$ & $\mathrm{N} 4 *$ \\
\hline $\begin{array}{l}\text { My best contacts for new product information often include people } \\
\text { online that I've never met face-to-face. }\end{array}$ & $\begin{array}{l}\text { Quand je cherche une information sur un nouveau produit, mes meilleurs } \\
\text { contacts incluent généralement des personnes sur Internet que je n'ai } \\
\text { jamais rencontrées en chair et en os. }\end{array}$ & $\mathrm{N} 5 *$ \\
\hline
\end{tabular}




\begin{tabular}{|c|c|c|}
\hline \multicolumn{2}{|c|}{ Marketing Literacy (L) } & \\
\hline $\begin{array}{l}\text { When viewing new advertising, I can identify the techniques being } \\
\text { used to persuade me to buy. }\end{array}$ & $\begin{array}{l}\text { Quand je vois une nouvelle publicité, je suis capable d'identifier les } \\
\text { techniques qui sont utilisées pour me persuader d'acheter. }\end{array}$ & L1 \\
\hline I am familiar with marketing jargon. & Je connais bien le « jargon $»$ marketing. & $\mathrm{L} 2$ \\
\hline $\begin{array}{l}\text { I'm really good at cutting through to the truth behind the over- } \\
\text { claiming in advertisements. }\end{array}$ & $\begin{array}{l}\text { J'arrive toujours à déceler la vérité qui se cache derrière les exagérations } \\
\text { des publicités. }\end{array}$ & L3 \\
\hline \multicolumn{3}{|c|}{ Consumer Self Efficacy (CF) } \\
\hline $\begin{array}{l}\text { I am confident at complaining to a firm when they don't give me } \\
\text { what I expect. }\end{array}$ & $\begin{array}{l}\text { Je n'hésite pas à me plaindre auprès d'une entreprise quand elle ne me } \\
\text { donne pas ce que j'attends. }\end{array}$ & $\mathrm{C} 1$ \\
\hline I am confident at telling organizations what I expect from them. & Je n'hésite pas à dire à une organisation ce que j'attends d'elle. & $\mathrm{C} 2$ \\
\hline $\begin{array}{l}\text { I am confident at working with large companies to get exactly what I } \\
\text { want from them. }\end{array}$ & $\begin{array}{l}\text { Je n'hésite pas à collaborer avec de grandes entreprises pour obtenir } \\
\text { exactement ce que je veux d'elles. }\end{array}$ & $\mathrm{C} 3$ \\
\hline \multicolumn{3}{|c|}{ Expectations (EX) } \\
\hline $\begin{array}{l}\text { I expect companies to make use of my personal information to give } \\
\text { me better service. }\end{array}$ & $\begin{array}{l}\text { J'attends des entreprises qu'elles utilisent mes informations personnelles } \\
\text { pour m'offrir un meilleur service. }\end{array}$ & $\mathrm{X} 1 *$ \\
\hline $\begin{array}{l}\text { I like a firm I have bought something from to keep me informed of } \\
\text { further offers. }\end{array}$ & $\begin{array}{l}\text { J'aime qu'une entreprise chez laquelle j'ai acheté quelque chose me } \\
\text { tienne informé(e) de ses nouvelles offres. }\end{array}$ & $\mathrm{X} 2 *$ \\
\hline $\begin{array}{l}\text { For the products and services that interest me I like to be kept } \\
\text { informed anywhere, anytime, including by SMS and email. }\end{array}$ & $\begin{array}{l}\text { Lorsque des produits ou des services m'intéressent, j'aime être tenu(e) } \\
\text { au courant n'importe où, n'importe quand, y compris par SMS et par e- } \\
\text { mail. }\end{array}$ & $\mathrm{X} 3 *$ \\
\hline
\end{tabular}

* Items retained in the 3-dimensional 10-item structure 